
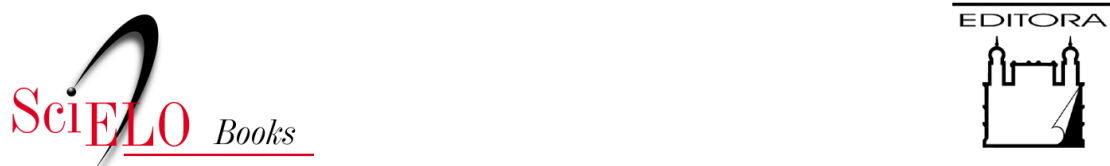

FIOCRUZ

\title{
7. "Agora não tem mais condições, eu não aguento mais!" \\ a perspectiva dos usuários
}

Armelle Giglio-Jacquemot

\section{SciELO Books / SciELO Livros / SciELO Libros}

GIGLIO-JACQUEMOT, A. "Agora não tem mais condições, eu não aguento mais!": a perspectiva dos usuários. In: Urgências $e$ emergências em saúde: perspectivas de profissionais e usuários [online]. Rio de Janeiro: Editora FIOCRUZ, 2005, pp. 121-132. Antropologia e Saúde collection. ISBN: 978-85-7541-378-4. https://doi.org/10.7476/9788575413784.0009.

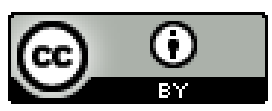

All the contents of this work, except where otherwise noted, is licensed under a Creative Commons Attribution 4.0 International license.

Todo o conteúdo deste trabalho, exceto quando houver ressalva, é publicado sob a licença Creative Commons Atribição 4.0.

Todo el contenido de esta obra, excepto donde se indique lo contrario, está bajo licencia de la licencia Creative Commons Reconocimento 4.0. 


\section{7 \\ "Agora Não Tem Mais Condicõoes,
Eu Não Agüento Mais!":
a perspectiva dos usuários}

E os usuários do sistema de atendimento às urgências e emergências? Será que para eles 'tudo é urgente', a menor 'febrezinha' ou 'dorzinha de cabeça', como costumam reclamar os diversos profissionais que, com ou sem formação médica, atuam na triagem das urgências?

As observações de campo mostram que, para apreender o que é urgente para eles, é preciso primeiro separar duas coisas que, por serem muitas vezes confundidas, desembocam nos julgamentos emitidos pelos agentes do sistema sobre o mau entendimento que os usuários têm do que é urgente no domínio da saúde. Faz-se necessário distinguir suas representaç̃oes da urgência da utilização que fazem do sistema de atendimento às urgências. De um lado, temos uma percepção, do outro, o uso de um recurso. $O$ entendimento da primeira não se deixa necessariamente deduzir do segundo, conforme um raciocínio que é muito comum nos agentes da triagem.

Por exemplo, como é comum mulheres dos meios populares levarem suas crianças pequenas com febre, mesmo que pouco elevada, para o pronto-socorro infantil, infere-se que essas mães consideram qualquer 'febrezinha' uma urgência. Essa conclusão é equivocada, pois o raciocínio que a sustenta parte do pressuposto de que os usuários recorrem ao sistema de atendimento para o que acham 'urgente', como se suas motivações correspondessem obviamente às funções explícitas desse sistema. Daí presume-se que se não fossem tão ignorantes fariam um uso mais adequado do prontosocorro e da ajuda móvel, e defende-se a idéia de que campanhas de informação ao público ou programas de educação em saúde constituem a resposta apropriada para reverter a situação.

Ora não é tão simples. A realidade dos comportamentos é a resultante da combinação de lógicas múltiplas, e se os usuários recorrem ao pronto-socorro para problemas ou situações de saúde que, de fato, acham urgentes, também o procuram para problemas que, mesmo para eles, não apresentam um caráter de urgência. Entretanto, nem por isso, deixam de esperar a satisfação do que vieram buscar, a saber, um atendimento.

As conversas e reações dos pacientes a respeito da demora e da ordem de passagem na sala de espera desvendam a avaliação, em termos de urgência e gravidade, que fazem de seu próprio problema de saúde. Se eles, freqüentemente, resmungam e se 
queixam do tempo longo da espera, também manifestam comiseração pelos pacientes que, segundo eles, "não podem esperar" e admitem facilmente que passem na sua frente. Escuta-se, por exemplo, os comentários seguintes: "os médicos estão ocupados com uma urgência"; "chegou uma urgência, atrasou tudo"; "tem uma urgência dentro". Aliás, os pacientes resignam-se com a espera na medida em que consideram que, à diferença de outros, seu problema não é insuportável e nem coloca, de imediato, sua vida em perigo. O atendimento não precisa ser urgente, o que importa é ser atendido. Muitos depoimentos apontam para esse fato como, por exemplo, a fala de uma mulher que esperava um atendimento há mais de duas horas na sala de espera do prontosocorro infantil, para sua filha pequena que estava com febre:

\begin{abstract}
Às vezes eu levo as crianças, às vezes é uma febre alta, às vezes é outra coisa, coisa que não acho assim urgente, se sabe que é um negócio assim controlável. Que dá para esperar um pouquinho. Então não estou agoniada que nem uma vez que quebrei o pé que eu vim para o PS. Ai, foi a única vez que eu fui assim pro PS, coisa que achei assim urgente. Que às vezes eu levo as crianças, vou no PS, mas não assim na urgência. Posso até esperar porque sei que vou ter um tratamento, não é? Então não é uma coisa assim... urgência... eu vou passar pelo PS e tal, no caso das crianças, mas o pé, não, o pé quebrado não dava para esperar.
\end{abstract}

As pessoas não recorrem sistematicamente à rede de atendimento às urgências para problemas de saúde que julgam urgentes. Esse fato merecia ser estabelecido antes de investigar o que é urgente para elas.

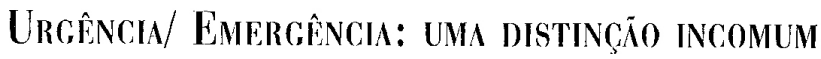

A palavra 'emergência' é pouco presente nas falas dos usuários, sendo as palavras 'urgência' e 'urgente' bem mais familiares. Para muitos, urgência e emergência "é a mesma coisa", eles não discriminam espontaneamente entre as duas. Quando usam a palavra 'emergência', geralmente é para designar as urgências que chegam ao prontosocorro de viatura de bombeiros, segundo uma assimilação forte da emergência com o Resgate. A essa também se sobrepõe outra, que, ligada à atuação visível dos bombeiros nos acidentes de trânsito, identifica 'caso muito sério' com 'intervenção do Resgate'. A emergência é, então, vista como uma urgência gravíssima, atendida rapidamente pelos bombeiros: "Quando vem de Resgate é emergência, se esperar morre" (trabalhadora doméstica, de uns 30 anos, que veio ao pronto-socorro de Rosália, de ambulância), "Quando você liga e é emergência, o Resgate vem em cinco minutos" (homem de uns 50 anos, que ligou para o 192 e conta que a ambulância demorou quatro horas até chegar).

Entretanto, as pessoas geralmente não estabelecem diferenças, em termos de graus de gravidade, entre urgência e emergência. Falam em urgência e quando querem significar que ela é grave dizem que "é muito urgente", que "é uma urgência mesmo". 


\section{Distanciar-se da Perspectiva Biomédica}

Para apreender o que os usuários consideram urgente no domínio da saúde, não se revela muito interessante nem pertinente ir à procura dos sinais físicos que se constituiriam para eles em indícios de urgência, no intuito de repertoriá-los. Não é dessa maneira que se pode esperar alcançar sua percepção da urgência, e isso, por duas razões. Primeiro, porque esta não se limita, nem se deixa reduzir, a simples sinais de ordem orgânica/corporal. Veremos que a leitura de um sintoma e a percepção de um problema como sendo de urgência geralmente estão ligadas não estritamente ao sintoma ou problema em si, mas ao contexto geral no qual eles se manifestam. Segundo, porque seguir essa premissa consiste em adotar a categoria biomédica de 'urgência' seu conteúdo e seus critérios - como referência implícita na investigação do que é urgente para os usuários, o que representa uma abordagem muito equivocada do ponto de vista antropológico.

Para compreender o que constitui uma urgência para os usuários, é preciso se distanciar do que é 'uma urgência médica' para os profissionais da saúde e não abordála a priori como estes a definem e a identificam, a saber, como um estado ou uma situação de saúde que coloca a vida em risco, e cuja avaliação se dá graças à leitura de sinais que têm sua sede e sua expressão no corpo. Para os usuários, os sintomas corporais não são necessariamente mais pertinentes e mais decisivos do que outros indicadores de natureza diversa que não se restringem ao corpo. Não se deve ignorar que a urgência, enquanto categoria biomédica, está intimamente ligada a uma certa concepção da saúde entendida em sua dimensão anatomofisiológica. Pautadas nela, as urgências/emergências biomédicas são identificadas em alterações e problemas que dizem respeito estritamente a essa esfera.

Ora, os usuários não têm concepções da saúde que necessariamente coincidem com a da biomedicina, e inúmeras pesquisas em antropologia médica mostram, ao contrário, que "o contexto, seja das relações sociais, seja do ambiente natural, faz parte também de possiveis fontes de sinais a serem considerados na tentativa de identificar a doença, suas causas e seu significado" (Langdon, 2003: 97). Em conseqüência, as concepções e o vivido que os indivíduos têm do que ameaça perigosamente a sua saúde (ou a de outrem) podem vir a ser bem diferentes dos que decorrem da perspectiva biomédica.

\section{A Urgência: uma CONSTRuç̃̃o CONTEXTUAL.}

Na sala de espera do pronto-socorro do Hospital das Clínicas, encontrei uma imensa quantidade de pessoas se queixando de uma variedade grande de sintomas, esperando um atendimento para um leque amplo de problemas que, tal como os formulavam, enquadravam-se dentro da saúde, entendida no seu sentido biomédico restrito: dor de cabeça, febre, fraqueza, pé torcido, cólica de rins, dor na coluna, na perna, tosse, falta de ar, tremedeira etc... Conversando ou caladas, esperavam a sua vez. Muitas não 
me pareciam estar ruins e a necessidade por elas manifestadas de um atendimento no pronto-socorro não ficava, de início, muito compreensível, sobretudo quando relacionada às suas desgastantes implicações: horas e horas de espera, perda de um dia de trabalho, obrigação de arrumar um esquema para a guarda das crianças deixadas em casa etc. Já me parecia muito mais óbvia a necessidade no caso das pessoas que expressavam muita dor ou que apresentavam problemas impressionantes.

Só entendi melhor quando o trabalho de campo se deslocou do pronto-socorro para a central de chamadas do 192, e que comecei a sair de ambulância em busca do atendimento solicitado. Porque então tive acesso a elementos de compreensão impossíveis de serem conseguidos a partir do pronto-socorro: com os motoristas, fui até onde moram os pacientes, descobri seus bairros, entrei em suas casas, vi e conheci os pacientes no meio de seus familiares, percebendo assim um pouco das relações existentes entre eles e interagindo também com todos. Em outros termos, recolhi dados relativos ao contexto no qual estão inseridos o paciente e seu problema, considerado e apresentado, por ele e/ou os seus familiares, como urgente. A partir da escuta, observação e vivência, compreendi que é a situação na qual se manifestam que, muitas vezes, confere a um sintoma - um estado de saúde - seu caráter urgente e, isso, à medida que eles também interferem e mexem com toda a situação. Assim, passei a entender como um problema sem caráter de gravidade para quem desconhece a situação pode ser lido como preocupante por quem está dentro dela; essa atribuição de gravidade só adquire sentido no seu contexto.

Para exemplificar, tomemos o caso de uma mulher idosa cuja filha ligou para a Central dizendo que sua mãe sofria de tuberculose, não parava de tossir e estava muito fraca. Depois da chegada da ambulância, deu para entender que a paciente, que de fato tossia muito e forte, morava com sua filha, genro e os três netos, e que, sendo a casa pequena, ela dormia no sofá da sala. As falas do casal revelaram que a mãe tossia, sobretudo à noite, e que seus acessos de tosse perturbavam o sono de toda a família, acordando as crianças $\mathrm{e}$, principalmente, o marido que tinha de "levantar todo dia às $5 \mathrm{~h}$ da manhã" para trabalhar e acabava passando noites em claro. Dava para perceber, nas entrelinhas, que essa situação, que durava há dias, tinha-se tornado intolerável.

A tosse da mãe tinha acabado de criar uma situação de urgência: estava colocando em risco a sobrevivência e o equilibrio dessa família pobre que dependia, em grande parte, da condição de trabalho do pai. Suportada por dias e noites sem sono, chegou a ser percebida como um problema grave: não só porque afetava a mãe, mas porque prejudicava física e moralmente toda a família; não em si, enquanto sintoma individualizado e isolado, mas enquanto manifestação criadora de uma situação que punha em perigo a vida da família. O problema da mãe constituía-se num problema para todos, urgente de ser resolvido. Para esse casal que queria, a todo custo, a internação da paciente no hospital, a solução passava aparentemente pelo afastamento imediato da mãe, já que os remédios (uma sacola plástica cheia) nâo tinham melhorado a tosse, apesar de "custarem muito caro".

É assim que uma tosse antiga e forte pode vir a ser considerada uma urgência. Dentro do pronto-socorro, separada de seu contexto, é pouco provável que ela seja 
vista dessa maneira. ' Os médicos podem até pensar que, sendo antiga, ela não apresenta nenhum caráter de urgência e talvez façam a sempiterna pergunta: "mas por que a paciente não veio antes?". Da mesma maneira, num outro contexto, num outro momento (no início, por exemplo), numa outra família (menos pobre, com casa maior, quartos fechados), essa tosse pode não vir a se tornar urgente. Mas dentro de seu contexto, ela chegou a representar um problema muito sério. O conhecimento do contexto é fundamental para entender as urgências dos usuários. É a razão pela qual não se pode dizer que 'a tosse' - ou qualquer outro sintoma - é vista por eles como um sinal de urgência. Seria uma generalização não só abusiva, mas errada, tendo em vista que apaga a importância do contexto na atribuição do caráter de urgência.

Aliás, neste caso, como em numerosos outros, não é tanto o sintoma assinalado que necessita de uma intervenção urgente, mas o contexto geral no qual se manifesta e que perturba: muitos sinais de urgência não se encontram inscritos no corpo do doente, mas fora dele, na situação que o envolve. No exemplo anteriormente citado, eles não são apenas a tosse da mãe, mas a falta de sono do marido e o risco de ele perder o trabalho, o perigo de a família ficar sem recursos, sem falar do cansaço e do nervosismo das crianças e da mulher, para citar somente os elementos ameaçadores que foi possível identificar durante a passada por essa casa. É a conjunção de todos os fatores que desemboca numa situação vivida como urgente e é ela que procura ser tratada com rapidez.

\section{A UrgênCIA: UMA CONSTRUÇão COLETIVA}

Se a percepção da urgência é, então, uma construção contextual que envolve sinais heterogêneos de perigo, ela também é uma construção profundamente coletiva da qual todos participam, isto é, não somente o doente, mas membros de sua família e até vizinhos. Aliás, nem sempre o paciente participa dessa construção, e os exemplos mais flagrantes de sua dimensão coletiva são certamente os dessas pessoas cujo estado de saúde é designado e apresentado por suas famílias/vizinhança como grave, mas que dizem estar bem e que não querem a ajuda de urgência e, ainda menos, de um atendimento. Quando os motoristas de ambulância chegam à casa desses pacientes, muitas vezes, os encontram em situações e num estado aparente que contrastam bastante com os da descrição dramática feita por telefone.

No exemplo anterior, é o casal que parece ter avaliado o problema da mãe e acionado o meio para tratá-lo. Não dá para saber se a mãe tomou parte dessa apreciação e associou-se à decisão, pois não abriu a boca em nenhum momento. De qualquer maneira, concordando ou não, ela se deixou tranqüilamente levar para o pronto-socorro. Agora, há numerosos casos em que a discordância é manifestada com força pelo paciente que se rebela e recusa abertamente a apreciação e a decisão impostas por seus familiares. Aí, a avaliação não é consensual e revela que atrás dela, atrás do pretenso problema de saúde que precisa ser atendido com urgência, outras coisas estão em jogo, outros perigos estão ameaçando. O que mais uma vez aponta para o caráter totalizante, 
e não restritamente médico, da percepção da urgência que encontra em riscos de várias ordens seus sinais de perigo.

No intuito de aprofundar essas colocações, vamos examinar o caso bem representativo ${ }^{2}$ de um homem de 56 anos, cuja mulher ligou para a Central do 192 dizendo que o marido era alcoólatra e a agredia, que no momento estava passando muito mal, que precisava ser tratado com urgência, pois bebia sem parar há alguns dias, apesar de o médico ter dito que não podia, "de jeito nenhum", por causa de uma cirurgia feita há alguns meses atrás. Expressando muita inquietação pelo estado de seu companheiro que, segundo ela, se encontrava muito ruim na cama no momento da ligação, ela pediu para a ambulância vir depressa.

Chegando lá, encontramos a mulher no portão de entrada da casa. Repetiu o que tinha dito por telefone e acrescentou outras queixas, enumeradas uma após a outra, numa logorréia irreprimível: seu marido bebia muito ("não sai do bar"), estava devendo três aluguéis, "água, luz, tudo", não queria trabalhar, mijava na cama, batia nela (já tinha feito um boletim de ocorrência na Delegacia da Mulher), tinha acabado de ameaçá-la fisicamente, falando o seguinte: "vou fechar a casa e vou te arrebentar". Enquanto falava, seu comportamento indicava que o marido não sabia da chamada: segurandonos no portão, o tempo de contar o que ele não deveria escutar, ela virava a cabeça de vez em quando para a casa, atenta e inquieta. Para pôr fïm na fala da mulher, o motorista falou: "deixa eu conversar com ele" e fez um movimento para entrar. Ela o deixou passar, declarando que ela "não tinha mais condição" e que o proprietário, "Seu Manoel", ia mandá-los "embora da casa". O motorista disse-lhe que seu marido provavelmente não ia querer ir ao hospital e the perguntou se ela concordava com o procedimento aplicado neste casos, a saber: "chamamos a polícia, nós amarramos ele na maca e vamos até o hospital". À sua pergunta -. "certo? posso fazer isso?" - a mulher deu uma resposta que manifestava claramente sua vontade: "Pode, claro, não posso ficar...". Indo à direção da casa, ela ainda falou que dormia no sofá da sala com duas facas de cozinha, pois seu marido tinha dito que ia esfaqueá-la durante o sono, o que sua vizinha confirmaria se estivesse presente. Em alguns minutos, então, o declarado grave problema de saúde do marido tinha passado ao segundo plano: quem precisava de ajuda era a mulher, quem estava em risco de vida era ela. Nas entrelinhas, seu discurso visava a convencer o motorista da realidade e da proximidade do perigo que a estava ameaçando, a saber: seu marido; se a ambulância não o levasse agora para o hospital, ela podia morrer, pois ele ia matá-la.

Entramos na sala da casinha miserável onde morava o casal. A mulher abriu a porta do quarto escuro no qual se encontrava seu marido, deitado na cama. Parecia estar dormindo e levou um susto quando nos viu. Colocando-se de lado, apoiado em seu braço, ele perguntou: "o que está acontecendo?". E, em seguida: "você é da onde?". O motorista, para quem estava olhando, respondeu: "somos do Hospital das Clínicas", e o homem imediatamente se rebelou: "não, não vou para lá, não, não preciso ir para lá, não. Estou bom, estou tranqüilo". O motorista procurou apaziguá-lo, tentando convencêlo de que ir para o hospital era bom para ele e que logo estaria de volta em casa: "Vai medir a pressão, o médico vai receitar um remédio para você, no caso de você ficar nervoso, essas coisas todas, aí a ambulância pega você e traz você de volta. 
Rapidinho!". "Não!", falou o homem. Neste momento, a mulher entrou na conversa, enfatizando o problema do marido e sua gravidade:

\begin{abstract}
Moço, moço! Ele fez uma operação, os médicos aqui não quis operar ele porque não tinha os aparelhos aqui... Precisou ir em São José do Rio Preto. Ele não pode beber, esse homem não pode beber. Ele operou em São José do Rio Preto. Esse homem morreu e viveu de novo, certo? Eu tenho tudo ai, guardado, eu tenho testemunhas!
\end{abstract}

O estado de saúde do homem tinha voltado ao primeiro plano. O motorista reforçou a fala da mulher, dizendo: "é perigoso, vai ter que fazer outra cirurgia, vamos lá, fazer um check-up geral e aí volta para cá, numa boa. (...) Você vai lá para dar uma geral, para ver, você não pode beber, está bebendo, pode prejudicar, você pode ter que fazer outra cirurgia futuramente". "Não, não preciso ir lá, não!", insistiu o homem. "Então pode deitar e ficar calmo", falou o motorista que saiu do quarto com a mulher desesperada: "eu chamo vocês de novo, pelo amor de Deus! Porque eu não posso. Eu fico pousando na casa dos outros... por causa...". O motorista saiu do quarto e, com um gesto firme da mão, indicou a saida para ela. Andando de volta para o portão, ele disse: "é o que falei para a senhora (...). Eu não posso pegar ele dentro da casa pela força e levar. Se a senhora permitir, eu vou chamar a polícia, pegamos ele, colocamos na maca...". "Tem que levar, sim!", disse ela chorando. "Então, deixa ele quietinho!". Fora da casa, o problema da saúde do marido ficou relegado, de novo, em segundo plano.

O motorista precisava telefonar para a polícia. Fomos juntos até um orelhão e, depois da ligação, voltamos para a frente da casa onde esperamos um bom tempo, na calçada, a chegada de um carro da polícia. Durante este tempo, a mulher continuou expondo suas recriminações. Não parava de falar, dando cada vez mais informações sobre o marido e seu comportamento, sobre ela e seus problemas por causa dele, sobre a vida que estavam levando juntos. De maneira desordenada, contou que ele a tinha espancado fazia 15 dias, que não sabia onde ele bebia, comentou que ele não tinha "precisão de estar atrasando o aluguel para Seu Manoel", falou que tinha "dez anos de prefeitura" e que estava "aposentado por causa dessa operação". Mas, acrescentou ela, "ele recebe dinheiro. Ele fala para mim que não recebe e vai pagar o bar. Está devendo três aluguéis para o homem. Eu não posso mais ficar nessas condições!". Ainda falou que "o pior é que ele não endireita, entâo tem que tomar uma solução", e, sem transição, apontou para seu estado de saúde, muito ruim por causa dele: "tomo cinco tipo de remédio: eu fiquei doente, eu tenho problema de cabeça por causa desse homem. (...) Eu tomo Diazepam, eu tomo Trepitanol, eu tomo um remédio para úlcera...". Foi neste momento que o marido apareceu na porta da casa. Estava saindo e se dirigindo em nossa direção, andando de maneira insegura. "Olha, ele, ele!", avisou a mulher que já tinha manifestado, várias vezes, seu receio de ele fugir antes da chegada da polícia. "Deixa ele sair. Depois nós vamos atrás dele, nós pegamos ele. Fique sossegada", respondeu o motorista com firmeza. O que veio a seguir foi inacreditável: o homem passou nos ignorando ao mesmo tempo que o motorista e a mulher desconheceram sua passagem. Só olharam para ele quando havia se afastado bastante. 
O marido foi embora enquanto ficamos na calçada, à espera da polícia. A muit:er continuou falando e fornecendo elementos que davam para entender sempre melhe: : que, na situação presente, a tinha levado a solicitar a Central e a pedir não somen:: : atendimento urgente, mas também a internação de seu marido. "Ele fez cirurgia ji quê?", perguntou o motorista. "Ele fez o tal de neurismo que se diz...", respondeu ela. acrescentando: "Sabe, tinha aparelho, se não ele morria... Agora ele vai querer me matar? (...) Estou avisando faz tempo, desde que a gente veio aqui: você não pode beber!. Já deu convulsão duas vezes, ele já quase morreu, eu que corro com esse homem..." . "A convulsão foi provocada pela bebida?", inquiriu o motorista. Ela respondeu:

É, por causa da bebida. Jáficou internado na Santa Casa uma semana, ficou no Hospital das Clínicas, sabe. (...) Esse homem não pára de beber e fica me agredindo desse jeito. O pior é o aluguel com o homem aqui. $O$ dinheiro da aposentadoria dele está para chegar e ele disse que vai pegar esse dinheiro e vai sumir no mundo, não vai pagar o homem aqui, o que que eu vou fazer? Não tenho casa própria ainda. Eu que tenho que pegar esse dinheiro. Fui lá no meu sogro antes de ontem, pousei nele ontem. Porque toda vez que vou lá, eu conto, eles perguntam, 'está cada vez pior', conto tudo que ele faz comigo aqui

Para resumir o fim desse caso, a polícia acabou chegando e, acompanhada pela ambulância (a mulher sentada na parte traseira), foi à procura do homem nas ruas da cidade e o encontrou num bar. "Não tem problema comigo", afirmou imediatamente ele para os policiais que foram até o balcão. "Vai lá, no hospital", respondeu um deles. "Para quê? Para que eu vou lá? Eu não vou, não!", reagiu o homem. Depois de conversas tensas centradas na necessidade de ele cuidar de seu problema de saúde - "é o que falei para você, vai passar por um médico, ele vai ver como está, depois volta para a casa", insistiu o motorista - ele acabou subindo na ambulância, na condição de não ser amarrado na maca. Os policiais foram embora, e a mulher foi levada ao pronto-socorro de carro particular por um conhecido do marido que, na lanchonete, tinha presenciado a cena toda.

\section{A UrGência: UMa CONGTElaç̃̃o de sinais de PERIGo}

O que leva a apreciar um problema de saúde urgente não são sinais que só dizem respeito a ele, mas sim a um conjunto de sinais de perigo que, por se juntarem todos ao mesmo tempo, configuram uma situação de alto risco que torna esse problema grave e urgente. No caso citado, os sinais de risco não são percebidos ou considerados pelo marido, mas pela mulher. São de várias ordens. No nível mais explícito do discurso, parece que o alcoolismo do homem e seu estado de saúde ruim a preocupam: "ele já quase morreu". O fato de ele estar alcoolizado o tempo todo - "ele bebe todo dia!"pode ter aumentado sua inquietação no momento. Mas, considerando-se somente esses problemas, não dá muito para entender por que vieram a se tornar tão urgentes na percepção da mulher, pois, não são novidade. Há os sinais ligados ao risco de agressão 
física. Mas, aí também, esse perigo faz parte do cotidiano da mulher já faz tempo. Entretanto, as ameaças de pancada e de morte recentemente proferidas pelo marido talvez tenham exacerbado seu temor. Da mesma forma, as dívidas do casal constituem um perigo sério, já que vivem numa condição miserável. Porém, também não são novidade: deu para saber que o casal está devendo, pelo menos, o pagamento de contas de luz, de água e três aluguéis. Mas aí o fato novo, o grande perigo ao qual o casal está agora exposto é a perda da moradia. Ele aterroriza a mulher: a questão dos aluguéis não pagos volta de maneira reiterada em sua fala e, entre todos os problemas que indica, é este que parece central para ela. O proprietário - o "Seu Manoel", ao qual ela sempre se refere e que passou em casa pouco tempo antes de ela chamar a Central - deve ter ameaçado o casal de expulsão: "Seu Manoel vai mandar nós embora de casa", "o pior é o aluguel com o homem aqui", "não vai pagar o homem aqui, o que é que eu vou fazer?".

Parece, então, que é o surgimento dessa ameaça iminente que passou a transformar o vivido de uma situação difícil no vivido de uma situação grave, porque além dos vários riscos que já pesam na existência dessa mulher, o que se delineia no horizonte imediato são a miséria absoluta, a degradação e a morte social, entre outras consequêencias terríveis. Sem casa, sem dinheiro, com um marido doente e alcoólatra, essa mulher vai para o 'fundo do poço'. Será que ela tem uma percepção errada da urgência quando avalia que os problemas de saúde do marido precisam ser tratados com urgência? Relacionados com os perigos aos quais expõem, é de convir que são muito preocupantes. $\mathrm{Se}$, nesse contexto muito problemático e precário, os donos da casinha tivessem continuado compreensivos, pode ser que o alcoolismo do marido, apesar de inquietante e assolador, não tivesse chegado a ser considerado pela mulher como necessitando uma intervenção tão imediata. Mas, uma vez que surgiu a ameaça séria de expulsão da casa, ele passou a se tornar um problema serí́ssimo.

Conhecendo alguns dos elementos de contexto que envolve o problema de saúde do marido dá, então, para entender porque está percebido como urgente e porque é tão importante para a solicitante seu marido ser rapidamente levado ao pronto-socorro e internado no hospital para fazer uma cura de desintoxicação. Porque assim, quem sabe, a saúde dele melhore, não beba mais ou beba menos, tenha mais dinheiro, fique mais fácil de conviver, não bata mais nela, não desapareça etc. Também, enquanto ele está internado no hospital, ela respira e se recupera um pouco, vive mais tranqüila. E, sobretudo, a pensão do marido estando "para chegar", é bem provável que, enquanto ele estiver preso no hospital, ela saque o dinheiro, pague uma parte dos aluguéis atrasados e tire assim de sua frente, por algum tempo, o grande perigo da perda da moradia.

Neste caso, como em muitos outros, os riscos e danos vividos como os mais graves não são os que ameaçam diretamente a saúde da pessoa para quem está explicitadamente solicitada a intervenção urgente, mas os que ela faz pesar nas existências das pessoas próximas (família, vizinhos). Afinal, é ela mesma que se constitui num perigo para os outros, para sua saúde ("eu fiquei doente, tenho problema de cabeça por causa desse homem", fala a mulher) e até para sua vida. Por isso, ela precisa ser tratada com urgência, isto é, antes de tudo, afastada da casa e mantida no hospital o maior tempo possivel: a ajuda pedida e oferecida diz menos respeito ao doente designado do que a seus familiares. 


\section{Os Urgentes 'Pequenos Problemas'}

É importante assinalar, também, a existência de um outro tipo de situação em que o problema de saúde, embora não sendo considerado pelos pacientes como uma ameaça séria para sua vida biológica representa, no entanto, para eles (e seus familiares) um perigo. É o caso desses aparentes 'pequenos problemas', que não são considerados urgentes pelos profissionais da saúde, e cujo pronto-socorro está repleto: são as dores de cabeça, cortes, sensações de fraqueza, tonturas, membros torcidos, dores na coluna, nas costas etc... Apesar de não pôr a vida das pessoas em risco, no sentido biomédico, eles a ameaçam e a dificultam seriamente. Existem outras mortes e outros sofrimentos a serem temidos do que os do corpo físico.

Para a empregada doméstica, a balconista, o pedreiro, o motorista, o peão, a mulher sozinha que tem vários filhos para criar, um pé torcido, tonturas, enxaquecas, dores nas costas, não são 'pequenos problemas'. Talvez o sejam no início de suas manifestações, mas com o tempo, vêm a se tornar seríssimos: alterando a capacidade no desempenho das atividades diárias, eles podem trazer enormes conseqüências, entre as quais, a perda do emprego. Nesse ponto, a percepção da urgência dos usuários entra em choque frontal com a dos profissionais da saúde. Com efeito, o papel do tempo na construção do que vem a ser considerado urgente pelos primeiros é muito diferente do que desempenha nas concepções biomédicas da urgência (normativas ou não). Foi demonstrado que, quanto mais um problema (um sintoma) é antigo, menos tende a ser considerado pelos médicos como urgente: é o caráter repentino de sua manifestação que aponta para seu possível caráter de urgência. Ora, na percepção dos usuários, o tempo geralmente trabalha no sentido exatamente contrário. É por sua persistência, através do tempo, que um problema (sintoma) vem a ser considerado urgente: em si, pois sua duração não habitual e o fracasso dos recursos terapêuticos usualmente utilizados acabam tornando-o muito anormal e preocupante; e no contexto onde se manifesta, pois sua permanência tem incidências cada vez mais negativas e pesadas sobre a vida. Uma cefaléia passageira, mesmo forte, pode não ser lida como um sinal de urgência. Mas uma que não passa ou volta sempre, desde dias, sim. É sua duração excepcional que alerta e que acaba tornando-a intolerável, urgente de ser tratada: por causa dos sintomas penosos, para se livrar da dor, das náuseas, da sensibilidade e irritabilidade extremas; por causa das perturbações que estes sintomas provocam nas relações e em todas as áreas da existência da pessoa.

Os 'pequenos problemas' levam os usuários a consultar no pronto-socorro porque atrapalham gravemente a vida cotidiana: no dominio social, familiar, conjugal, profissional, econômico, eles ameaçam piorar desequilíbrios existentes ou ainda romper equilíbrios, já muito frágeis, dificilmente conseguidos e mantidos por parte dos que recorrem à rede pública de atendimento às urgências/emergências, a saber, na sua maioria, pessoas das camadas socioeconômicas mais baixas. Devido à precariedade de seus meios e condições de existência, muitas delas já vivem 'normalmente' numa situação de urgência permanente e com poucas garantias contra as ameaças de toda ordem que potencialmente as cercam. Sobrevivem mais do que vivem, e sua sobrevivência depen- 
de fundamentalmente de seu estado de saúde, ou melhor, de estarem em condição de poder cumprir, física e mentalmente, as tarefas do dia-a-dia. Em um contexto geral de urgência e insegurança, muitos 'pequenos' problemas de saúde podem vir a se tornar grandes.

Os dados de campo mostram que não existe, enquanto tal, uma nosografia popular da urgência médica: ao contrário, assinalam a importância fundamental do contexto na atribuição do caráter urgente e o caráter, muitas vezes, pluridimensional do objeto desta atribuição. Entretanto, uma generalidade, nada surpreendente, pode ser estabelecida, no que diz respeito aos sintomas considerados urgentes pelos usuários, no domínio da saúde estritamente anatomofisiológica. Tudo que é vivido como colocando em risco a capacidade de trabalhar (trabalho doméstico ou remunerado), tudo que a altera, a diminui, a impossibilita, constitui-se num perigo grave, num problema urgente a ser tratado: uma enxaqueca rebelde como uma perna quebrada, uma sensação durável de fraqueza como uma paralisia repentina.

\section{A Saúde Adinte}

Nas urgências dos usuários, tudo gira em torno do problema de saúde sem que este seja necessariamente, no fundo, o verdadeiro problema. Contudo, é interessante notar que é sempre dele que explicitamente se trata e a propósito do qual se fala, e isso mesmo quando está manifestadamente ocupando um lugar secundário: é ele que está evidenciado pelos usuários em seus pedidos de atendimento, quer seja pelos atendentes das centrais, quer seja pelo pessoal que atua no pronto-socorro; é a ele que os atendentes e motoristas também dirigem suas falas e perguntas nas interações com os pacientes e solicitantes.

É como se todos os atores implicados fizessem de conta, tacitamente, de que se trata, somente, ou antes de tudo, de cuidar de urgências que dizem respeito à vida biológica e que, por isso, exigem uma atuação médica. Mesmo quando os solicitantes, uma vez conseguida a chegada da ambulância, expressam e mesclam, em um discurso muitas vezes confuso - à imagem da mulher de nosso exemplo - todas suas queixas e motivos médicos e extramédicos, os motoristas continuam imperturbáveis a focalizar suas falas sobre o declarado problema de saúde e sobre o doente para os quais foram chamados. Todos desempenham o papel esperado e, sobretudo, formalmente previsto pelo dispositivo de atendimento às urgências e emergências médicas, pelo qual trabalham ou ao qual apelam. Somente o paciente (ou a vítima) designado é que, às vezes, se rebela, recusando a etiqueta de doente sério que lhe é imposta: mesmo assim, é tratado como se precisasse de um atendimento médico e levado para o pronto-socorro. Quaisquer que sejam as diversas razões que podem explicar esse consenso de todos em torno do caráter médico das urgências atendidas, ${ }^{3}$ o fato é que ele abandona logicamente à biomedicina e aos seus representantes o tratamento de problemas para os quais estes não constituem necessariamente a resposta apropriada ou única, isto é, que não podem resolver (curar) ou mesmo melhorar. 
NoTAS

1 Aliás, a tosse é citada com freqüência pelos triadores do sistema como o exemplo, por excelência, do não urgente.

2 Este caso, que foi filmado, está apresentado no documentário etnográfico "Urgences" (Giglio-Jacquemot, 2002).

3 Cuja investigação e discussão deixamos para um outro trabalho. 